\title{
Comparison of fecal culture and F57 real-time polymerase chain reaction for the detection of Mycobacterium avium subspecies paratuberculosis in Swiss cattle herds with a history of paratuberculosis
}

\author{
Selina M Keller ${ }^{1}$, Roger Stephan², Rahel Kuenzler ${ }^{3}$, Mireille Meylan and Max M Wittenbrink ${ }^{1 *}$
}

\begin{abstract}
Background: Bovine paratuberculosis is an incurable chronic granulomatous enteritis caused by Mycobacterium avium subspecies paratuberculosis (MAP). The prevalence of MAP in the Swiss cattle population is hard to estimate, since only a few cases of clinical paratuberculosis are reported to the Swiss Federal Food Safety and Veterinary Office each year.

Fecal samples from 1,339 cattle (855 animals from 12 dairy herds, 484 animals from 11 suckling cow herds, all herds with a history of sporadic paratuberculosis) were investigated by culture and real-time polymerase chain reaction (PCR) for shedding of MAP.

Results: By culture, MAP was detected in 62 of 445 fecal pools (13.9\%), whereas PCR detected MAP in 9 of 445 pools (2.0\%). All 186 samples of the 62 culture-positive pools were reanalyzed individually. By culture, MAP was grown from 59 individual samples (31.7\%), whereas PCR detected MAP in 12 individual samples (6.5\%), all of which came from animals showing symptoms of paratuberculosis during the study. Overall, MAP was detected in 10 out of 12 dairy herds (83.3\%) and in 8 out of 11 suckling cow herds (72.7\%).

Conclusions: There is a serious clinically inapparent MAP reservoir in the Swiss cattle population. PCR cannot replace culture to identify individual MAP shedders but is suitable to identify MAP-infected herds, given that the amount of MAP shed in feces is increasing in diseased animals or in animals in the phase of transition to clinical disease.
\end{abstract}

Keywords: Mycobacterium avium subspecies paratuberculosis, Cattle, Feces, Culture, PCR

\section{Background}

Mycobacterium avium subspecies paratuberculosis (MAP) is the etiological agent of paratuberculosis (Johne's disease), an incurable chronic granulomatous enteritis primarily affecting wild and domestic ruminants. MAP-infected cattle may have implications for public health, because the agent is putatively linked to a human chronic granulomatous ileitis described as Crohn's disease [1]. In the dairy industry, paratuberculosis has been globally recognized as an important

\footnotetext{
* Correspondence: wittenbr@vetbakt.uzh.ch

${ }^{1}$ Institute of Veterinary Bacteriology, Vetsuisse Faculty, University of Zurich,

Winterthurerstrasse 270, CH-8057 Zurich, Switzerland

Full list of author information is available at the end of the article
}

cause of morbidity and hence of significant economic loss [2]. In European countries, the prevalence of paratuberculosis amongst cattle is approximately $20 \%$ [3]. In Switzerland, the rate is considerably lower, i.e. $10 \%$ on average $[4,5]$. However, the significance of MAP as a pathogen in the Swiss cattle population is hard to estimate. On average, only 15 cases of clinical bovine paratuberculosis-out of an overall cattle population of approximately 1.6 million animals-are reported to the Swiss Federal Food Safety and Veterinary Office (FSVO) each year.

Bearing this in mind, systematic analyses of the prevalence of MAP in Swiss dairy cattle are indicated. Paratuberculosis is mainly diagnosed by means of direct confirmation 
of MAP in feces, either by culture or by targeting specific MAP gene sequences with polymerase chain reaction (PCR). The sensitivity of both culture and PCR are dependent on the stage of infection of individual animals. Irregular fecal shedding of (usually few) MAP cells occurs during the preclinical stage, whereas high numbers of MAP are shed during the late clinical stage [2]. Culture methods, although with an estimated sensitivity of maximally $60 \%$ not ideal, are considered the reference diagnostic tests for the direct detection of MAP in fecal samples $[2,6]$. PCR is often examined as an alternative to bacterial culture but is generally considered less sensitive than culture [2]. In comparison to culture as the reference method, a correlation between MAP numbers excreted in feces and the detection rate by PCR is evident: With so-called heavy shedders, PCR has a sensitivity of 80 to $100 \%$, but PCR is not effective for the detection of cattle shedding low numbers of MAP [7-9].

In order to estimate the prevalence of MAP in the Swiss cattle population, we analyzed fecal samples of 1,339 cattle from herds with a history of sporadic paratuberculosis. We do not know how often the different stages of infection with MAP occur in indigenous cattle. Therefore, we conducted a systematic comparison of conventional culture and real-time PCR. This should prove which method provides a higher likelihood for the direct detection of MAP in fecal specimens from non-clinical cattle from indigenous herds with a history of sporadic paratuberculosis.

\section{Methods}

\section{Animals and samples}

The present study involved 1,339 cattle from 23 herds, i.e. 855 animals (including 7 bulls) from 12 dairy herds and 484 animals (including 22 bulls) from 11 suckling cow herds. Herd sizes ranged from 11 to 130 animals. The average age in the dairy herds was 4.2 years (minimum: 10 months, maximum: 13 years), and in the suckling cow herds it was 4.8 years (minimum: 11 months, maximum: 17 years). During the last 5 years, the FSVO registration office of notifiable diseases was informed of at least one animal per herd with confirmed paratuberculosis.

Fecal samples were collected over a period of 5 months, i.e. from February to July 2011. Samples were taken from the animals' rectum by glove and without lubricant, subsequently chilled and then stored at $-20^{\circ} \mathrm{C}$ until testing (for a maximum period of 3 months). At the time of sampling, all animals were clinically healthy, except for three cows presenting symptoms of paratuberculosis (2 cows from suckling cow herds; one cow from a dairy herd). Another 14 animals from 9 herds ( 7 animals from 3 suckling cow herds; 7 animals from 6 dairy herds) developed symptoms indicative of paratuberculosis (weight loss, reduced milk yield, intermittent diarrhea) without symptoms of general disease during an average time period of 7 months after sampling (minimum: 1 month, maximum: 16 months).

\section{Pooling and decontamination procedure}

Fecal samples were assayed in batches according to their sampling date. Individual samples were pooled solely within the same herd. Thus, most pools consisted of three individual samples, with two or four samples also being possible. Pooling was performed by weighing $2.0 \mathrm{~g}$ of feces from each of the 3 animals into a sterile $50 \mathrm{ml}$ polycarbonate screw capped tube (Becton Dickinson, Basel, Switzerland). $8.0 \mathrm{ml}$ of sterile water and glass beads ( $4 \mathrm{~mm} \varnothing$, Faust, Schaffhausen, Switzerland) were added to improve homogenization by vigorous vortexing. Subsequently, two $3.0 \mathrm{ml}$ aliquots of the homogenate were subjected to the decontamination procedure according to Beerwerth [10]. Briefly, each $3 \mathrm{ml}$ aliquot was homogenized in $40 \mathrm{ml}$ of $4.0 \% \mathrm{NaOH}$ (Roth, Karlsruhe, Germany) with glass beads by repeated agitation on a vortexer, shaken for a further $8 \mathrm{~min}$ on a horizontal shaker and then allowed to stand for $2 \mathrm{~min}$ in order for gross particles to settle. The supernatants were then pooled. Upon centrifugation $\left(3000 \times \mathrm{g}, 15 \mathrm{~min}, 20^{\circ} \mathrm{C}\right)$ the pellet was resuspended by thorough repeated agitation on a vortexer (in $20 \mathrm{ml}$ of $5 \%$ oxalic acid) and then shaken for $15 \mathrm{~min}$ on a horizontal shaker. The suspension was centrifuged as described above. The pellet was then suspended once again in $6 \mathrm{ml}$ of sterile saline $(0.15 \mathrm{M} \mathrm{NaCl})$ and used as inoculum.

\section{Culture}

Loewenstein-Jensen (LJ) medium containing $2.0 \mathrm{mg} / \mathrm{l}$ mycobactin J (Enclit, Oelzschau, Germany) and Herrold's Egg Yolk Agar (HEYA) with 2.0 mg/l mycobactin J, 50 mg/ $\mathrm{ml}$ vancomycin, $50 \mu \mathrm{g} / \mathrm{ml}$ of nalidixic acid, and $50 \mu \mathrm{g} / \mathrm{ml}$ of amphotericin B (Becton Dickinson, Basel, Switzerland) were used as culture media. $200 \mu$ l aliquots of the inoculum were transferred to each of two slants of LJ and HEYA, respectively. The inoculated tubes were left to stand for $1 \mathrm{~h}$ at ambient temperature so that the agar surface was horizontal, thus permitting maximum absorption of the inoculum on to the agar surface [11]. Cultures were incubated at $37^{\circ} \mathrm{C}$ for 16 weeks and inspected for growth of MAP at biweekly intervals. MAP was preliminarily diagnosed on the basis of colony morphology (small, smooth to slightly rough, opaque to whitish colonies). All presumptive positive colonies were picked up with sterile swabs and transferred into $3 \mathrm{ml}$ of Middlebrook $7 \mathrm{H} 9$ broth, supplemented with ADC-enrichment (Becton Dickinson, Basel, Switzerland) and $2.0 \mathrm{mg} / \mathrm{l}$ mycobactin J (Synbiotics Europe, Lyon, France). Broth cultures were incubated for at least one week at $37^{\circ} \mathrm{C}$ and microscopically tested for acid-fast staining bacteria, following Ziehl-Neelsen staining [12]. All cultures with mycobacterial growth confirmed by microscopy were subjected 
to a F57-PCR specific for MAP. Fecal samples of all pools testing positive for MAP were reanalyzed individually by culture and PCR in order to identify the MAP shedders.

\section{Preparation of genomic DNA from fecal samples}

A DNA extraction method described in detail previously was used to isolate genomic DNA from bovine feces $[13,14]$. Briefly, approximately 500 to $700 \mathrm{mg}$ from each fecal specimen were resuspended in $2.0 \mathrm{ml}$ of 0.15 M phosphate buffered saline (PBS, $136.9 \mathrm{mM} \mathrm{NaCl}$, $1.46 \mathrm{mM}$ KH2PO4, 8.1 mM Na2HPO4 × 2H2O, $2.7 \mathrm{mM}$ $\mathrm{KCl}, \mathrm{pH}$ 7.4). $100 \mu \mathrm{L}$ of the sample suspensions were mixed with $130 \mu \mathrm{L}$ lysis buffer and $20 \mu \mathrm{L}$ of Proteinase $\mathrm{K}$ provided in the MaGNA Pure DNA Isolation Kit III (Roche Molecular Diagnostics, Penzberg, Germany) and incubated for $30 \mathrm{~min}$ at $65^{\circ} \mathrm{C}$ and $10 \mathrm{~min}$ at $95^{\circ} \mathrm{C}$. The mixtures were transferred onto a bead-beating matrix in MagNA lyser tubes (Roche). A mechanical lysis step consisting of $60 \mathrm{~s}$ at $6,500 \mathrm{rpm}$ followed by $60 \mathrm{~s}$ on a cooling block held at $4^{\circ} \mathrm{C}$ was performed three times on the samples. $100 \mu \mathrm{L}$ of sample lysates were transferred to the MagNA Pure LC instrument sample cartridge. DNA was automatically isolated from these samples using the MagNA Pure LC instrument and in accordance with the protocol of the MagNA Pure LC DNA Isolation Kit III. Purified DNA templates were eluted in $100 \mu \mathrm{L}$ of elution buffer provided in the DNA isolation kit. A $2 \mu \mathrm{L}$ aliquot from the final eluate was used as a template for PCR.

\section{Real-time PCR}

A real-time PCR protocol for analysis of bovine milk and feces targeting a 254-bp fragment within the MAP-specific F57 sequence and a 257-bp internal control (IC) template was used $[13,14]$. PCR reactions were carried out in the LightCycler 2.0 instrument (Roche Molecular Diagnostics) in a total reaction volume of $20 \mu \mathrm{l}$ in glass capillary tubes. The reaction mixture contained $1 \times$ LightCyclerFaststart DNA master plus hybridization probes mix (Roche Molecular Diagnostics), $1 \mu \mathrm{M}$ of each primer (MAP f57p1, MAP f57p2), $200 \mathrm{nM}$ of each LC probe (MAP f57-3'Fluo, MAP f57-5'LC Red 640, puC19-5'LC Red 705), $2 \mu$ I DNA template (original concentration of the extracted DNA), and 20 DNA copies of IC template. The amplification consisted of an initial pre-incubation step at $95^{\circ} \mathrm{C}$ for $10 \mathrm{~min}$ to activate the DNA polymerase, followed by 45 cycles of $95^{\circ} \mathrm{C}$ for $10 \mathrm{~s}, 56^{\circ} \mathrm{C}$ for $20 \mathrm{~s}$, and $72^{\circ} \mathrm{C}$ for $18 \mathrm{~s}$. The fluorescence signals corresponding to the F57 sequence target and the IC template amplification were monitored during the $56^{\circ} \mathrm{C}$ annealing step in the LC Red $640 \mathrm{~nm}$ and LC Red 705 detection channels of the LightCycler 2.0 instrument, respectively.

\section{Results}

By culture, MAP was detected in 62 of the 445 fecal pools (13.9\%). In detail, 48 isolates $(77.4 \%)$ were grown only on HEYA, 2 (3.2\%) only on LJ, and 12 (19.4\%) on both HEYA and LJ. MAP was grown within 9 to 11 weeks of incubation. Of the 1,780 cultures (445 pools, 4 agar slants per pool), 16 (0.9\%) were heavily contaminated by constituents of the bovine fecal flora and were thus excluded. However, investigation of the pools in question could be finalized, since there was only one medium tube per pool that could not be evaluated. Using F57 real-time PCR, MAP was detected directly in 9 of the 445 pools $(2.0 \%)$.

To identify the MAP shedders, all 186 samples of the 62 culture-positive pools were reanalyzed individually by culture and by PCR. MAP was isolated from 59 of the 186 individual samples $(31.7 \%)$, representing 50 of the 62 MAP-positive pools (80.6\%). In detail, we identified 43 pools with 1 positive sample, 5 pools with 2 positive samples, and 2 pools with 3 positive samples ( $\Sigma 59$ MAP isolates). By PCR, MAP was detected directly in 12 samples $(6.5 \%)$ from 11 pools (10 pools with 1 positive sample; 1 pool with 2 positive samples). All PCR-positive samples also tested positive by culture. None of the culture-negative samples tested positive by PCR. Overall, MAP was detected in 10 out of 12 dairy herds $(83.3 \%)$ as well as in 8 out of 11 suckling cow herds (72.7\%).

Out of the 1,339 cattle a total of 17 animals showed symptoms of paratuberculosis either when the samples were taken ( $\mathrm{n}=3$ ), or over an average duration of 7 months after sampling (re. Methods). By culture, MAP was detected in fecal samples of all 17 animals. PCR detected MAP in fecal samples from 12 of the 17 animals (70.6\%).

\section{Discussion}

In the present study, we investigated a total of 1,336 fecal specimens from predominantly healthy cattle belonging to herds with a history of sporadic paratuberculosis. This sample collection provides a valid basis for a comparison of PCR and culture to detect MAP in feces from cattle without clinical signs of paratuberculosis. The cultural assay is significantly more sensitive than the F57 real-time PCR for this specific purpose. Cultivation of MAP proved to be successful in 62 fecal pools $(13.9 \%)$ as well as in 59 of the 186 individual fecal samples (31.7\%), whereas only 9 fecal pools (2.0\%) and 12 individual fecal samples (6.5\%) tested positive with PCR. It is noteworthy that only 50 of the 62 MAP-positive pools $(80.6 \%)$ were confirmed by isolation of MAP from the individual samples. Culturing a single fecal specimen has a sensitivity of maximally $60 \%$ [2]. Thus, it is not unlikely that repeated analysis of a paucibacillary sample with inhomogeneously distributed MAP cells reveals a negative result. All in all, our finding of a considerably 
higher analytical sensitivity of culture for samples from non-clinical animals is in agreement with the literature [7-9].

PCR methods for MAP are considered less sensitive than bacterial culture for the following reasons: In comparison to diseased cattle, MAP-infected cattle in the preclinical stage only shed small amounts of bacteria in their feces [7-9,15,16]. The chance of detecting such small bacterial counts is much more likely in culture, because a much larger inoculum can be tested than with PCR. According to our protocol, the inoculum for culture was equivalent to $336 \mathrm{mg}$ of feces per pool or individual sample. This amount was inoculated onto four agar slants which were subsequently incubated for 16 weeks and examined for growth of MAP at least 8 times (every other week). By comparison, the template for our PCR consisted of a DNA extract equivalent to $0.24 \mathrm{mg}$ feces per PCR reaction. Hence the aliquot subjected to culture was 1,400 times higher than the aliquot analyzed by PCR.

In preceding evaluation studies, our DNA extraction and PCR protocol revealed a reproducible limit of detection (LOD) of $7 \mathrm{fg}$ purified genomic MAP-DNA (arithmetically 1.4 MAP-DNA copies) per $\mu$ PCR template, equivalent to a LOD of $3.9 \times 10^{3}$ MAP cells per gram feces in our study $[13,14]$. In comparison, an inoculum for the in vitro-growth of MAP needs to contain 50 viable mycobacteria on average $[17,18]$. Therefore, for the cultural growth of MAP according to our protocol, a fecal sample must contain no less than $5.9 \times 10^{2}$ of MAP per gram of feces, which is approximately one sixth of the MAP counts required for a positive PCR. The much higher rate of MAP detection in culture than with PCR can also be led back to the fact that we subcultivated all MAP-suspected colonies systematically. An average of two subcultures per sample was applied, taking into consideration all samples (445 pools, 186 individual samples). These considerations explain why culture is more suitable than PCR to identify animals with asymptomatic intestinal MAP infections and low bacterial shedding.

MAP culture is very labor-intensive and thus probably less feasible for routine diagnostics. The validity of PCR for monitoring bovine herds affected by paratuberculosis had to be assessed further. Our tests have proven that the state of MAP infection in herds can be determined by PCR quite clearly with animals upon the onset of paratuberculosis symptoms, because cattle shed larger amounts of bacteria in the clinical state of paratuberculosis $(2,15,16)$. Since also non-clinical animals - or as in our study animals in the phase of transition to clinical disease - can shed MAP in large numbers, our PCR protocol should enable the rapid screening of herds for heavy fecal shedders, the detection of which is more critical for herd control [9]. Applying only PCR is problematic when dealing with herds where, as was the case in our study, mainly low shedders are to be expected. In our study, 6 out of 18 MAP-positive herds (30.0\%) could not be detected by PCR. A recent paper refers to the fact that the systematic optimization of the DNA extraction may allow the sensitivity of the PCR to meet the sensitivity of culture [19]. However, it remains unaddressed if an approximately 8 times higher sensitivity of PCR in comparison to culture $[20,21]$ is solely based on an optimized DNA extraction. In any case, this important technical aspect must be verified within the scope of further systematic studies.

In the literature, various approaches to grow MAP from bovine feces are described without any one standard being generally accepted. This applies, in particular, to the decontamination of fecal samples (maximum inactivation of fecal bacterial contaminants whilst preserving viability of MAP). We decided to ensure decontamination by means of $\mathrm{NaOH}$ and oxalic acid. This method has been described several times as being quite effective, because very few cultures are lost due to an overgrowth by contaminants from the fecal flora $[4,10,11,22-26]$. $\mathrm{NaOH}$ is mainly advantageous because an alkaline environment causes less damage to mycobacteria than an acidic environment $[27,28]$. According to our results, alkali-coupled oxalic acid treatment introduced in mycobacteriological diagnostics 83 years ago [29] leads to a considerably higher detection rate of mycobacteria from feces than other decontamination methods.

\section{Conclusions}

Compared to a F57 real-time PCR, culture is more sensitive for the detection of fecal MAP shedding in nonclinical cases of bovine paratuberculosis. Thus, PCR cannot replace culture to detect individual non-clinical MAP shedders. However, our F57 real-time PCR is suitable to identify MAP-infected herds if single animals are shedding MAP in larger numbers. These cattle are highly contagious in terms of risk of transmission to susceptible cattle. In our study, all MAP-shedders identified directly by PCR showed symptoms of paratuberculosis either at the time of sampling or during an average time period of 7 months after sampling. In Switzerland, cattle herds with sporadic clinical cases of paratuberculosis pose a serious risk of MAP-transmission to other herds due to the considerable rate of non-clinical fecal shedders.

\section{Competing interests}

The authors declare that they have no competing interests.

\section{Authors' contributions}

SMK performed all analyses under supervision of MMW and RS. SMK and MMW drafted the manuscript. MM, RS, and MMW participated in the design of the study. RK carried out the sampling of specimens from cattle with data collection and analysis under supervision of MM. All authors have read, participated in and approved the final manuscript. 


\section{Acknowledgements}

This research was funded by a grant of the Swiss Federal Food Safety and Veterinary Office (FSVO). We wish to thank Nicole Cernela for her excellent technical assistance.

\section{Author details}

${ }^{1}$ Institute of Veterinary Bacteriology, Vetsuisse Faculty, University of Zurich, Winterthurerstrasse 270, CH-8057 Zurich, Switzerland. ${ }^{2}$ Institute for Food Safety and Hygiene, Vetsuisse Faculty, University of Zurich, Winterthurerstrasse 270, 8057 Zurich, Switzerland. ${ }^{3}$ Clinic for Ruminants, Vetsuisse Faculty, University of Berne, Bremgartenstrasse 109a, 3012 Berne, Switzerland.

Received: 8 April 2014 Accepted: 3 October 2014

Published online: 10 October 2014

\section{References}

1. Feller M, Huwiler K, Stephan R, Furrer HJ, Pfyffer G, Jemmi T, Baumgartner A, Altpeter E, Shang A, Egger M: Mycobacterium avium ssp. paratuberculosis and Morbus Crohn: systematic review and meta-analysis. Lancet Infect Dis 2007, 7:607-613.

2. Timms VJ, Gehringer MM, Mitchell HM, Daskalopoulos G, Neilan BA: How accurately can we detect Mycobacterium avium subsp. paratuberculosis infection? J Microbiol Methods 2011, 85:1-8.

3. Nielsen SS, Toft N: A review of prevalences of paratuberculosis in farmed animals in Europe. Prev Vet Med 2009, 88:1-14.

4. Glanemann B, Hoelzle LE, Boegli-Stuber K, Jemmi T, Wittenbrink MM: Detection of Mycobacterium avium subspecies paratuberculosis in Swiss dairy cattle by culture and serology. Schweiz Arch Tierheilk 2004, 146:409-415.

5. Bögli-Stuber K, Kohler C, Seitert G, Glanemann B, Antognoli MC, Salman MD, Wittenbrink MM, Wittwer M, Wassenaar T, Jemmi T, Bissig-Choisat B: Detection of Mycobacterium avium subspecies paratuberculosis in Swiss dairy cattle by real-time PCR and culture: a comparison of the two assays. J Appl Microbiol 2005, 99:587-597.

6. Whitlock RH, Wells SJ, Sweeney RW, Van Tiem J: ELISA and fecal culture for paratuberculosis (Johne's disease): sensitivity and specificity of each method. Vet Microbiol 2000, 77:387-398.

7. Clark DL, Koziczkowski JJ, Radcliff RP, Carlson RA, Ellingson JL: Detection of Mycobacterium avium subspecies paratuberculosis: comparing fecal culture versus serum enzyme-linked immunosorbent assay and direct fecal polymerase chain reaction. J Dairy Sci 2008, 91:2620-2627.

8. Taddei S, Robbi C, Cesena C, Rossi I, Schiano E, Arrigoni N, Vicenzoni G, Cavirani S: Detection of Mycobacterium avium subsp. paratuberculosis in bovine fecal samples: comparison of three polymerase chain reaction-based diagnostic tests with a conventional culture method. J Vet Diagn Invest 2004, 16:503-508

9. Wells SJ, Collins MT, Faaberg KS, Wees C, Tavornpanich S, Petrini KR, Collins JE, Cernicchiaro N, Whitlock RH: Evaluation of a rapid fecal PCR test for detection of Mycobacterium avium subsp. paratuberculosis in dairy cattle. Clin Vaccine Immunol 2006, 13:1125-1130.

10. Beerwerth $\mathrm{W}$ : The culture of mycobacteria from feces of domestic animals and their significance for epidemiology and control of tuberculosis [in German]. Prax Pneumol 1967, 21:189-202.

11. Kalis CH, Hesselink JW, Russchen EW, Barkema HW, Collins MT, Visser IJ: Factors influencing the isolation of Mycobacterium avium subsp. paratuberculosis from bovine fecal samples. J Vet Diagn Invest 1999, 11:345-351.

12. Ziehl FHP: On the staining of the tubercle bacillus [in German]. Dtsch Med Wochenschr 1882, 8:451.

13. Tasara T, Stephan R: Development of an F57 sequence-based real-time PCR assay for detection of Mycobacterium avium subsp. paratuberculosis in milk. Appl Environ Microbiol 2005, 71:5957-5968.

14. Bosshard C, Stephan R, Tasara T: Application of an F57 sequence-based real-time PCR assay for Mycobacterium paratuberculosis detection in bulk tank raw milk and slaughtered healthy dairy cows. J Food Prot 2006, 69:1662-1667.

15. Chiodini RJ, Rossiter CA: Paratuberculosis: a potential zoonosis? Vet Clin North Am Food Anim Pract 1996, 12:457-467.

16. Collins MT, Gardner IA, Garry FB, Roussel AJ, Wells SJ: Consensus recommendations on diagnostic testing for the detection of paratuberculosis in cattle in the United States. J Am Vet Med Assoc 2006, 229:1912-1919.
17. Krebs A: Guidelines for the Bacteriological Diagnosis of Tuberculosis [in German]. Jena: VEB Gustav Fischer Verlag; 1964.

18. Kralik P, Beran V, Pavlik I: Enumeration of Mycobacterium avium subsp. paratuberculosis by quantitative real-time PCR, culture on solid media and optical densitometry. BMC Res Notes 2012, 5:114. doi:10.1186/1756-0500-5-114.

19. Leite FL, Stokes KD, Robbe-Austerman S, Stabel JR: Comparison of fecal DNA extraction kits for the detection of Mycobacterium avium subsp. paratuberculosis by polymerase chain reaction. J Vet Diagn Invest 2013, 5:27-34.

20. Logar K, Kopinc R, Bandelj P, Staric J, Lapanje A, Ocepek M: Evaluation of combined high-efficiency DNA extraction and real-time PCR for detection of Mycobacterium avium subsp. paratuberculosis in subclinically infected dairy cattle: comparison with faecal culture, milk real-time PCR and milk ELISA. BMC Vet Res 2012, 8:49. doi:10.1186/1746-6148-8-49.

21. Hanifian S, Khani S, Barzegari A, Shayegh J: Quantitative real-time PCR and culture examination of Mycobacterium avium subsp. paratuberculosis at farm level. Vet Microbiol 2013, 162:160-165.

22. Kalis CH, Hesselink JW, Barkema HW, Collins MT: Culture of strategically pooled bovine fecal samples as a method to screen herds for paratuberculosis. J Vet Diagn Invest 2000, 12:547-551.

23. Nielsen SS, Gronbaek C, Agger JF, Houe H: Maximum-likelihood estimation of sensitivity and specificity of ELISAs and faecal culture for diagnosis of paratuberculosis. Prev Vet Med 2002, 53:191-204

24. Nielsen SS, Kolmos B, Christoffersen AB: Comparison of contamination and growth of Mycobacterium avium subsp. paratuberculosis on two different media. J Appl Microbiol 2004, 96:149-153.

25. Vasnick E, de Rijk P, Vercammen F, Rigouts L, Portaels F, Geysen D: A DNA sequence capture extraction method for detection of Mycobacterium avium subspecies paratuberculosis in feces and tissue samples. Vet Microbiol 2007, 122:166-171.

26. Fernandez-Silva JA, Abdulmawjood A, Akineden O, Bülte M: Serological and molecular detection of Mycobacterium avium subsp. paratuberculosis in cattle of dairy herds in Colombia. Trop Anim Health Prod 2011, 43:1501-1507.

27. Gray DF, Clarke BL, Johnstone WE: Detection of small numbers of tubercle bacilli in diagnosis; the lethal action of concentrating agents. Am Rev Tuberc 1954, 89:991-1001.

28. Patterson RA, Thomspon TL, Larsen DH: The use of zephiran in the isolation of M. tuberculosis. Am Rev Tuberc 1956, 74:284-288.

29. Corper HJ, Uyei N: Oxalic acid as a reagent for isolating tubercle bacilli and a study of the growth of acid fast nonpathogens on different mediums with their reaction to chemical reagents. J Lab Clin Med 1930, 15:348-369.

doi:10.1186/s13028-014-0068-9

Cite this article as: Keller et al:: Comparison of fecal culture and F57 real-time polymerase chain reaction for the detection of Mycobacterium avium subspecies paratuberculosis in Swiss cattle herds with a history of paratuberculosis. Acta Veterinaria Scandinavica 2014 56:68.

\section{Submit your next manuscript to BioMed Central and take full advantage of:}

- Convenient online submission

- Thorough peer review

- No space constraints or color figure charges

- Immediate publication on acceptance

- Inclusion in PubMed, CAS, Scopus and Google Scholar

- Research which is freely available for redistribution 